\title{
Challenges and Opportunities in Wearable Systems
}

\author{
David Kotz \\ Dartmouth College \\ David.F.Kotz@dartmouth.edu
}

\begin{abstract}
Wearable systems offer great promise in application domains as varied as healthcare, eldercare, augmented work, education, athletics, entertainment, parenting, travel, and personal productivity. In this keynote lecture I outline some of these opportunities and identify some of the many challenges we face in developing wearable technology that realize those opportunities. Notably, I anticipate wearable technology raising significant security risks and privacy issues - challenges we must address as we design and develop wearable devices, systems, and applications if we hope to see this technology widely accepted and adopted. Strong (and usable) security mechanisms are essential for safety-critical applications; meaningful privacy protections are essential for systems that accompany us through our private and public life. By raising these concerns today, I seek to ensure the wearable systems of tomorrow will have strong and usable security and privacy properties.
\end{abstract}

\section{Author Keywords}

wearable computing; mobile health; mHealth; security; privacy; wearable sensing; actuation.

\section{BIOGRAPHY}

David Kotz is the Champion International Professor in the Department of Computer Science at Dartmouth College. He served as Associate Dean of the Faculty for the Sciences for six years and as the Executive Director of the Institute for Security Technology Studies for four years. He served on the US Healthcare IT Policy Committee from 2013-17. His research interests include security and privacy, pervasive computing for healthcare, and wireless networks. He has published over 130 refereed journal and conference papers and obtained over $\$ 65 \mathrm{~m}$ in grant funding. He leads a fiveuniversity team investigating Trustworthy Health \& Wellness technology (see THaW.org), a collaborative effort to develop the Amulet wearable computing platform (see Amulet-project.org), and a collaborative team developing the Auracle wearable for eating detection (see Auracleproject.org). He is an IEEE Fellow, a Senior Member of the ACM, a 2008 Fulbright Fellow to India, and an elected member of Phi Beta Kappa.

After receiving his A.B. in Computer Science and Physics from Dartmouth in 1986, he completed his Ph.D in Computer Science from Duke University in 1991 and returned to Dartmouth to join the faculty. For more information see http://www.cs.dartmouth.edu/ dfk/.

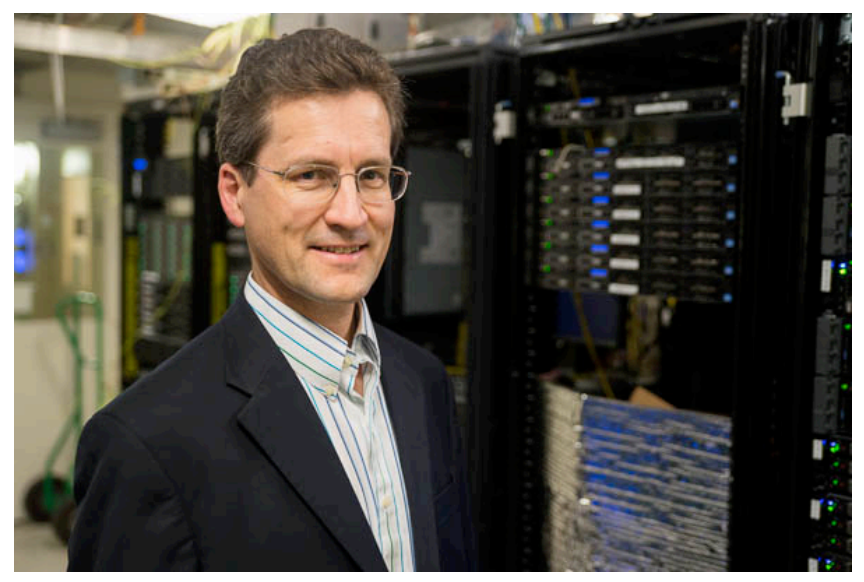

Permission to make digital or hard copies of part or all of this work for personal or classroom use is granted without fee provided that copies are not made or distributed for profit or commercial advantage and that copies bear this notice and the full citation on the first page. Copyrights for third-party components of this work must be honored. For all other uses, contact the Owner/Author(s). Copyright is held by the owner/author(s). WearSys'17, June 19, 2017, Niagara Falls, NY, USA.

ACM ISBN 978-1-4503-4959-8/17/06.

DOI: http://dx.doi.org/10.1145/3089351.3089821 